\title{
Reducing Medical Downgrading In A High Readiness Royal Marine Unit
}

\author{
J H ayton
}

\section{ABSTRACT}

\section{Objective}

This 3 year retrospective observational study aims to determine the diagnoses causing medical downgrading in a high readiness Royal Marine Commando unit, and to direct future investment to reduce numbers downgraded.

\section{Methods}

Medical and administrative records were used to ascertain diagnoses, aetiology, time downgraded, and whether men returned to full duties.

\section{Results \\ 4.4\% of unit strength was lost through medical downgrading. $43 \%$ was due to soft tissue lower limb injuries, of which $41 \%$ was due to anterior knee pain syndrome Low back pain accounts for $24 \%$ of the total. Median length of downgrading episodes was 3 months (range 1-40 months). Low back pain and lower limb soft tissue related episodes were longer (median 9 months $p=0.001$, and 10 months $p=0.003$ respectively). Fractures (median 2 months $p<0.001$ ) and general surgical problems (median 2 months $p=0.013$ ) were shorter than the overall mean. Orthopaedic conditions related to overuse had longer periods of downgrading (median 6 months) compared to trauma (median 3 months $p=0.01$ ). $9.3 \%$ of completed episodes of downgrading resulted in a medical discharge and $1.9 \%$ in a permanently reduced medical category.}

\section{Conclusions}

Conditions that respond rapidly to secondary care interventions have shorter episodes of downgrading compared to overuse conditions. Therefore, prevention and improved rehabilitation facilities are likely to be more effective than further secondary care investment in reducing medical downgrading. More timely use of permanent medical downgrading and medical discharge could reduce temporary downgrading by $\mathbf{2 0 \%}$.

$M$ edical Officer

45 Commando Royal $M$ arines

Email:hayton@doctors.org.uk

\section{Introduction}

$M$ ilitary personnel are required to maintain a high level of physical fitness and to be able to deploy to areas of the world where healthcare is not easily accessible. Placing of servicemen and women into medical categories is a key responsibility of the service doctor. This protects the individual by preventing their work exacerbating their condition. It also minimises the considerable burden of medical evacuations from operational theatres (1).

The burden of large numbers of nondeployable personnel presents particular difficulties to high readiness units, such as Royal $\mathrm{M}$ arine $\mathrm{Commandos,}$ which regularly deploy at short notice to remote locations. In planning services the Senior M edical Officer, HQ 3 Commando Brigade Royal M arines, assumes $5 \%$ of the men of a $\mathrm{C}$ ommando unit may be non-deployable due to medical reasons. From the operational perspective, this significantly reduces the fighting effectiveness of the unit, and contributes to the overstretch experienced by fit personnel. Combating this is one of the cornerstones of the D efence H ealth Plan (2).

Studies of medically downgraded personnel have focused on the diagnoses of illnesses and injuries affecting service personnel. Work in the UK and worldwide has used easily available data such as hospital admissions (3) or medical discharge from service (invaliding) (4). Data collected centrally by the Defence Analytical Services A gency relies on reports submitted by busy medical centres. Published studies of the prevalence of military morbidity in individual units have been mainly restricted to the controlled environments of recruit training establishments $(5,6)$. Such data is unlikely to reflect the true picture in a specialist unit such as 45 Commando Royal M arines (45 C do RM ).

$45 \mathrm{C}$ do RM is one of the three Commando units within the Royal $M$ arines. It has a strength of approximately 800 , including an attached Royal Artillery Battery. During the period of this study the unit was exceptionally active, conducting operations in the Balkans and Afghanistan, and exercises in N orway, O man, and Belize.

This retrospective observational study aims to accurately ascertain the diagnoses behind medical downgrades in a high readiness unit. It also aims to reduce the loss of fighting effectiveness by informed directing of medical effort and resources to those conditions that impact most on deployability. 


\section{Methods}

Weekly sick lists for the 3 year period from 1 January 2000 to 31 December 2002 were reviewed in conjunction with signal logs to identify all personnel in a reduced medical category. Information on diagnosis, likely aetiology (in the case of orthopaedic conditions), and outcome (upgraded vs. medical discharge) was obtained from review of the clinical notes held on the EMIS consultation system or from medical documentation. The primary diagnosis used by the downgrading doctor at the initial downgrading was used. Every month, or part thereof, of an episode of downgrading was recorded as one man-month. All missing or incomplete records, particularly when personnel were drafted, were followed up with other RM medical centres.

A database was constructed using $M$ icrosoft Excel software. Statistical analysis was performed using Excel and SPSS packages. $P$ values were calculated using the $\mathrm{M}$ ann-Whitney $\mathrm{U}$ test.

\section{Results}

During the study period, 162 completed episodes of downgrading were recorded in 160 men. Thirty five episodes started before the study period and 30 were ongoing at the end, although 19 of these had concluded at the time of writing. A total of 25,920 manmonths of downgrading occurred over the 3 years, equating to $4.4 \%$ of unit strength. T he breakdown per diagnostic category is shown in F igures 1 and 2. Primary diagnosis at time of downgrading was noted in all cases. Likely aetiology was determined in 120 of 121 of the orthopaedic episodes as either overuse or trauma.

The median length of completed episodes was 3 months with a range of 1-40 months. L ow back pain episodes were of significantly longer duration, while fractures and general surgery diagnoses had shorter episode lengths (Table 1 ). N o significant differences in outcome in the diagnostic categories were noted.

Fifteen (9.3\%) episodes of downgrading resulted in a medical discharge and $3(1.9 \%)$ were retained in a permanently reduced category. A further $4(2.5 \%)$ left the service while downgraded. $\mathrm{N}$ o significant differences in rates of medical discharge in the diagnostic groups were identified. Twenty two (13.8\%) patients were drafted to another unit while downgraded and $2(1.3 \%)$ servicemen were posted to $45 \mathrm{C}$ do $\mathrm{RM}$ having been downgraded elsewhere.

Of the 121 orthopaedic episodes completed, 61 were related to either overuse or degenerative changes. Fifty nine cases were directly related to trauma and one case was due to joint infection, not fitting either category. Overuse conditions had longer periods of downgrading (median 6 months), compared to traumatic cases (median 3 months $p=<0.001$ )

Limiting all temporary medical downgrading to a period of one year would reduce the total downgrading by 5,210 manmonths $(20.1 \%)$. If this could be achieved for low back pain and anterior knee pain, it would reduce overall downgrading by 2,281 man-months $(8.8 \%)$.

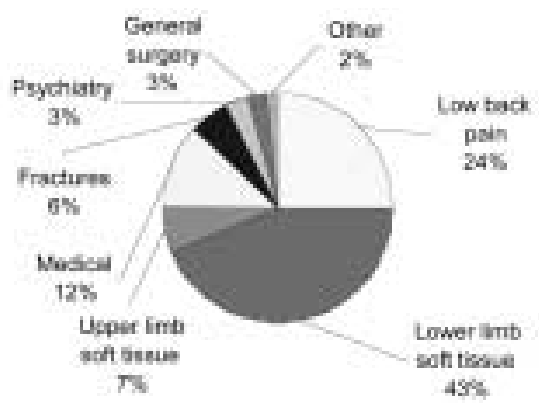

Fig 1. Percentage of total man-months of downgrading per diagnostic category 2000-2002 45 C do RM .

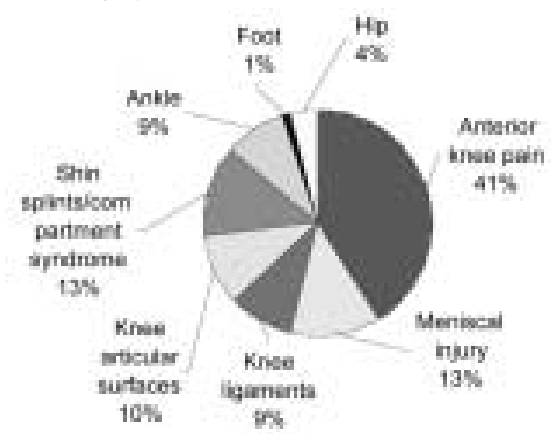

F ig 2. D iagnoses of soft tissue lower limb injuries, percentage of total man months of downgrading 2000-2002 $45 \mathrm{Cdo}$ RM .

Table 1. Length of downgrading episode per diagnostic category compared to population mean 2000-2002 45 C do R M .

\begin{tabular}{|l|l|l|l|l|l|}
\hline C ategory & $\mathrm{n}$ & M edian & $\begin{array}{l}\text { Range } \\
\text { (months) }\end{array}$ & $\begin{array}{l}\text { Interquartile } \\
\text { range }\end{array}$ & $\mathrm{P}$ value \\
\hline Low back pain & 28 & 9 & $1-25$ & $4-17$ & 0.001 \\
\hline Soft tissue lower limbs & 51 & 10 & $1-40$ & $3-13$ & 0.003 \\
\hline Soft tissue upper limbs & 14 & 4 & $1-21$ & $3-6$ & 0.984 \\
\hline Psychiatry & 7 & 4 & $1-9$ & $3-5$ & 0.819 \\
\hline Fractures & 25 & 2 & $1-8$ & $1-3$ & $<0.001$ \\
\hline Medical & 23 & 2 & $1-14$ & $1-4$ & 0.063 \\
\hline General surgery & 11 & 2 & $1-10$ & $2-2$ & 0.013 \\
\hline Other & 3 & 6 & $2-11$ & $\mathrm{~N} / \mathrm{A}$ & 0.676 \\
\hline ALL CATE GORIES & $\mathbf{1 6 2}$ & $\mathbf{3}$ & $\mathbf{1 - 4 0}$ & $\mathbf{2 - 1 0}$ & - \\
\hline
\end{tabular}




\section{Discussion}

Overall rates of medical downgrades of $4.4 \%$ in this study confirm the levels of around $5 \%$ for Royal $M$ arine units. 3.6\% of the fighting strength was lost through musculoskeletal injuries. This compares favourably with $6 \%$ in the Army (7), although a more useful comparison would be a similar light infantry unit.

The exclusive use of the EMIS computer system for consultation records, combined with the command requirement for regular accurate sicklists, resulted in no downgraded $M$ arines being lost to follow up. Downgraded personnel who were drafted to another unit were easily traced to other medical facilities due to the small size of the Royal $M$ arines.

U sing a month, or part thereof, to record length of downgrading is an effective overestimate. However, downgrading decisions were usually made for one, two, or three month periods. The downgrading decision was reviewed at the end of this period. The impact of hospitalisation and sick leave on numbers of personnel unfit to deploy was assumed to be negligible.

Prevention and appropriate timely treatment are important in minimising downgrading. This is of concern to the individual and to the wider Service. Overstretch within the Armed Forces due to downgrading has attracted considerable interest. A number of initiatives have been implemented, the evaluation of which has been predominantly retrospective.

\section{Secondary CareWaiting List}

\section{Initiatives}

A perception exists that rapid access to these facilities through private means would have a significant impact on downgrading. The experience within the Royal N avy and Royal $M$ arines was superficially promising with $72 \%$ of the 450 cases treated on a fast track iniative achieving $\mathrm{P} 2$ within a mean period of 29 weeks (8). 45 C do RM has made limited use of these initiatives referring two patients within the study period. This may have been partly due to the geographical remoteness of the unit from the medical facilities participating in the $\mathrm{RN}$ rapid treatment schemes, and partly due to the use of the out-patient clinics in M RS E dinburgh.

The profile of diagnoses within the unit suggests that increased spending on secondary care is unlikely to be effective. The two largest contributors to total downgrading, low back pain $(24 \%)$ and anterior knee pain (18\%), are principally managed without surgery. In the field of orthopaedics, the traumatic injuries which are more likely to respond rapidly to surgical intervention already have shorter periods of downgrading (median 3 months). Therefore, minimising waiting time for surgery will only have a limited effect on reducing the overall period of downgrading. However, rapid secondary care treatment would reduce the frustration felt when conditions known to respond rapidly to surgery, for example meniscal injuries, have to wait even short periods.

\section{Rehabilitation Facilities}

Seventy four per cent of man-months of downgrading was due to soft tissue orthopaedic diagnoses, with overuse or degenerative conditions having longer periods of downgrading compared to traumatic cases. These cases are most frequently treated conservatively. Evidence for the effectiveness of physiotherapy and rehabilitation is mixed. A study of a rehabilitation facility for trained ranks in Colchester was descriptive (9) and did not conclude on effectiveness. A randomised controlled trial of low back pain in civilian practice concluded physiotherapy was more effective in outcome and more cost effective than general practitioner management (10). A recent review of military rehabilitation concluded that the balance of current evidence supports its effectiveness (11).

45 C do RM has recently opened a Primary $\mathrm{C}$ are R ehabilitation F acility staffed by a Remedial Instructor to work with the existing physiotherapy service. The impact of this is being closely monitored.

\section{Primary Care}

$45 \mathrm{C}$ do RM has a $G$ eneral Duties M edical O fficer (M O) (SHO 1 level) who is assisted by a Civilian M edical Practitioner (CM P) working 8 hours per week. $N$ either of these doctors has specific training in soft tissue orthopaedics, nor is it included within their job descriptions. The two most common soft tissue problems seen over the study period, low back pain (24\%) and anterior knee pain $(18 \%)$, could predominantly be managed in primary care $(12,13)$. The impact that more specific training for these doctors would have on overall rates of downgrading is uncertain.

Clinical protocols, with a military emphasis, are currently being developed within the unit for low back pain and anterior knee pain. The Royal College of General Practitioners low back pain guidelines (12) are in use, although not audited, at present. Service wide treatment protocols were not available during the study period, and are not currently used in the study unit.

\section{Medical Board of Survey (MBOS) and Medical Discharge} Identifying personnel for either permanent medical downgrading and re-employment, 
or medical discharge, assists in reducing the operational burden of temporary medical downgrading. Any member of the RM who is temporarily medically downgraded for 12 months is required to be referred to the MBOS (14). This board can then decide to make a permanent medical downgrading, continue with a temporary category, or medically discharge the individual.

The extended periods of temporary downgrading noted in this study (up to 40 months) suggests that this is not occuring. Appropriate employment of those retained in service in a permanently reduced medical category is crucial to avoid their skills being wasted. Permanently downgraded Royal $M$ arines can and should deploy within the restrictions of their medical category.

\section{Prevention}

Changes in Royal $M$ arine basic training to make the physical aspects more progressive, while maintaining the final standards, have been impressive in reducing injury rates (15). Evidence to support training modification in trained ranks is less clear, but low levels of physical fitness are a risk factor for injury (16). This may occur after a long leave period.

T raining modifications to reduce lower limb and low back injuries are likely to be effective, particularly as overuse injuries typically have a longer period of downgrading. H owever, further studies into this area are required.

\section{Conclusion}

Reducing temporary medical downgrading has an important part to play in maintaining fighting effectiveness. C onsiderable resources have been directed at secondary care and rehabilitation. Within this unit, the likely impact of further secondary care spending is likely to be small. The effect of improved rehabilitation facilities has some supporting evidence, but full evaluation is required. $\mathrm{H}$ igh levels of soft tissue orthopaedic problems within $45 \mathrm{C}$ do RM support the current levels of investment in this area. It also supports injury prevention programs and more timely use of the MBOS and permanent downgrading.

\section{Acknowledgements}

$\mathrm{M}$ any thanks to $\mathrm{M} \mathrm{r} \mathrm{M}$ alcolm Woollard for assistance with statistical analysis and Dr Andrene $\mathrm{H}$ amilton for proof reading the manuscripts.

\section{References}

1. Croft AM, H opkins JP. M edical repatriations from Operation Resolute (Bosnia). J R A rmy M ed Corps 1997; 143(1):39-43.

2. D efence $\mathrm{H}$ ealth Programme 2004/2008.

3. Lauder TD, Baker SP, Smith GS, Lincoln AE. Sports and physical training injury hospitalization in the Army. American J ournal of Preventative M edicine 2000; 18 (3 Suppl):118-28.

4. Bergman BP, M iller SA. U nfit for further service: trends in medical discharge from the British Army 1861-1998. J R Army M ed Corps 2000: 146(3):204-11.

5. Jones $\mathrm{BH}, \mathrm{C}$ owan $\mathrm{DN}$, Tomlinson JP, Robinson JR, Polly DW, Frykman PN. Epidemiology of injuries associated with physical training among young men in the army. M edicine and Science in Sports and Exercise. 1993; 25(2):197-203.

6. Piantanida NA, K napik JJ, Brannen S, O'C onner $\mathrm{F}$. Injuries during $\mathrm{M}$ arine Corps officer basic training. M ilitary M edicine 2000; 165(7):515-20.

7. The Army Primary $\mathrm{H}$ ealth $\mathrm{C}$ are Study - Feb 01

8. 2SL Waiting L ist Initiative/ D M SD Pilot: Access to fast track treatment. M DG(N)/1790/2/8/1 D ated $28 \mathrm{Feb} 03$.

9. Stowbridge $\mathrm{N}$, Burgess $\mathrm{K}$. Sports and training injuries in British soldiers: $T$ he $C$ olchester garrison sports injury rehabilitation centre. J R A rmy M ed Corps 2002; 148(3):236-43.

10. M offett JK, Torgerson D, Bell-Syer S, Jackson $D$, Llewlyn-Phillips $\mathrm{H}$, Farrin A, Barber J. Randomised controlled trial of exercise for low back pain; clinical outcomes, costs, and preferences. B M J 1999; 319(7205):279-83.

11. Effectiveness of rehabilitation. $\mathrm{D} / \mathrm{AM} \mathrm{D} / \mathrm{PHC} / 58 / 11$ Dated 18 Oct 02.

12. The Royal College of General Practitioners. Clinical Guidelines for the $M$ anagement of Acute Low Back Pain.

13. Hull JB, Hobbs C, Sidebottom S. Anterior K nee Pain Syndrome. A review of current concepts and controversies. I R Army Med Corps 1999; 145(2):89-94

14. BR 1991. Instructions for the Royal $\mathrm{N}$ aval medical Service.

15. A review of the progressive nature of physical training to train RM Commandos. Institute of N aval M edicine Report No 98025 M ay 1998.

16. N eely F G. Intrinsic risk factors for exercise related lower limb injuries. Sports M edicine 1998; 26(4):253-63. 